\title{
Fibrinolytic agents in the treatment of tuberculous meningitis
}

\author{
JOHN LORBER
}

From the Children's Hospital, Sheffield

Tuberculous meningitis first became treatable in 1947 when streptomycin was introduced. It was soon found that one of the major drawbacks to the efficacy of treatment and a potent cause of mortality or of residual sequelae was the frequent occurrence of blocks in the cerebrospinal pathways. These resulted from a deposition of fibrinous exudate combined with tuberculous granulation tissue. This exudate was most damaging and prominent around the brain-stem and in the cisterns at the base of the brain. In this situation it interfered with the normal absorption of the cerebrospinal fluid and hence led to an obstructive, communicating hydrocephalus. In a consecutive series of 58 of our cases of tuberculous meningitis treated during 1949 and 1950, routine pneumoencephalography disclosed the presence of tentorial blocks leading to hydrocephalus in 36 children (Lorber, 1951b). Such basal exudate frequently calcified and was demonstrable on radiographs of the skull (Lorber, 1958). These calcified masses often harboured tubercle bacilli for years and were a potential source of relapse. The longest time between a first and second attack of meningitis was nine years. Another common site of the exudate was in the spinal subarachnoid space, and in 20 of our first 82 cases this led to a complete spinal block, interfering with the free penetration of streptomycin and necessitating cisternal injection for local treatment (Illingworth and Lorber, 1951). It seemed, therefore, that the use of a fibrinolytic agent, which could prevent blockage in the circulation of cerebrospinal fluid could be of value. In 1949, Cathie published results of a series of cases in which streptokinase was used intrathecally and he claimed improvement, but there were no concurrent controls. Nevertheless, streptokinase was of great potential interest, and hence I carried out a controlled clinical trial during 1950 (Lorber, 1951a). In this trial 24 new, previously untreated cases were allocated by random sampling into one of two groups. Their treatment was identical, consisting of intramuscular and intrathecal streptomycin, but one group of 12 children was also given 6 units of streptokinase (Burroughs Wellcome) in each intrathecal injection of streptomycin. This solution was active in vitro; it dissolved the fibrin clot formed in the cerebrospinal fluid from cases of tuberculous meningitis, using a dilution comparable to that obtained in vivo. On admission the two groups of children were comparable in every respect and none had spinal blocks. The results of the trial were disappointing. Seven out of 12 in each group survived, but four children treated with streptokinase developed complete spinal block as compared with only one among the controls. Intracranial blocks developed with equal frequency in the treated and control cases. Finally, streptokinase was far from free of side-effects; it often caused fever, headache, drowsiness, and excessive pleocytosis in the cerebrospinal fluid. It was therefore concluded that streptokinase was an unsuitable method of auxiliary treatment in tuberculous meningitis. Later, in 1954, Brooks, Fletcher, and Wilson studied the spinal cord complications in tuberculous meningitis in adults and as a result of their studies, Fletcher (1954) carried out a laboratory investigation of the potential value of streptokinase. He found that the plasminogen content was much higher in the cerebrospinal fluid of patients with tuberculous meningitis than in normal cerebrospinal fluid and that especially high levels were present in patients with spinal blocks. Antiplasmin was also present in all specimens. For this reason the addition of streptokinase to these fluids led to a low conversion rate to plasmin. He found that the quantity of streptokinase which produced lytic activity was so high that it would have been unsafe to use it clinically. Nevertheless, he used streptokinase in patients in larger doses than in my own experiment, but was unable to dissolve existing spinal blocks and considered that the irritative effect of the streptokinase nullified its potential therapeutic action.

This was a great disappointment. Meanwhile, however, P.A.S., and then in 1952, isoniazid were introduced as antituberculous drugs, and with their continued use there was a very great improvement in the results of treatment and a considerable decrease in the incidence of spinal and tentorial blocks. Only one child out of our first 51 treated with 
isoniazid combined with streptomycin and P.A.S. developed complete spinal block. Nevertheless this problem and that of tentorial blocks remained an important clinical feature. From 1955 onwards it became increasingly apparent from a large volume of unfortunately uncontrolled observations that the intrathecal injection of hydrocortisone might be more efficient and less dangerous than streptokinase was. Since 1957 I have used intrathecal injection of hydrocortisone in 12 out of 26 children treated in the past six years. The dose was 10 to $20 \mathrm{mg}$. per injection and was always associated with streptomycin, isoniazid, and penicillin to prevent accidental infection by pyogenic organisms. In eight of the 12 the indication was threatened or established spinal block. In two of them the spinal block was already well established before admission, and in these the hydrocortisone treatment was ineffective. In the other six the spinal block, however, either had just appeared or was impending as shown by a rapidly rising lumbar cerebrospinal fluid protein content (300 to $900 \mathrm{mg} . \%$ ) together with xanthochromia and low cerebrospinal fluid pressure. In these six the effect of hydrocortisone was prompt and dramatic, but it was a matter of trial and error for how long such treatment had to be continued. If the injections were abandoned too soon there was a tendency for the patient to relapse. This, however, was easily reversible by further treatment. Intra- thecal hydrocortisone was not very effective i楼 cases of tentorial block. Of five children with such: blocks two died with gross hydrocephalus and the three survivors are all severely handicapped bo mental and neurological sequelae. In conclusion it appears that hydrocortisone given intrathecally i⿳亠丷厂 a valuable adjuvant and a good fibrinolytic agent i the treatment of tuberculous meningitis with threatened spinal block. Its effectiveness, if any, in fully established spinal or tentorial blocks is doubtful.

\section{REFERENCES}

Brooks, W. D. W., Fletcher, A. P., and Wilson, R. R. (1954). Quari J. Med., 23, 275.

Cathie, I. A. B. (1949). Lancet, 1, 441.

Fletcher, A. P. (1954). J. clin. Invest., 33, 69.

Illingworth, R. S., and Lorber, J. (1951). Lancet, 2, 511.

Lorber, J. (1951 a). Ibid., 2, 1334.

- (1951b). Arch. Dis. Childh., 26, 28.

- (1958). Amer. Rev. Tuberc., 78, 38.

DR. MCNICOL questioned Dr. Lorber's assumption that hydrocortisone acted as a fibrinolytic agent, and fely that both streptokinase and urokinase would be worth of closer scrutiny.

DR. LORBER replied that evidence for hydrocortisone being a fibrinolytic agent was indeed scanty. The opportunity for further trials of such therapeutic agent in tuberculous meningitis had probably passed, since the number of new cases admitted was now very small. 